\title{
HSV-pneumonitis in a patient with lung cancer receiving check point inhibitors - a case report
}

\author{
Johannes Sumer ${ }^{1 *}$ D, Frederike Waldeck', Nadja Fischer ${ }^{2}$, Christina Appenzeller ${ }^{3,4}$, Markus Koster ${ }^{5}$, \\ Martin Früh ${ }^{3,4}$ and Werner C. Albrich ${ }^{1}$
}

\begin{abstract}
Background: Herpes simplex virus (HSV) is commonly associated with oro-facial and genital manifestations. It rarely causes encephalitis and even less commonly, in heavily immunosuppressed patients, visceral disease or bronchopneumonitis. We present a case of cytologically-proven, PCR-positive HSV-1 tracheobronchitis and pneumonitis in a patient with less severe immunocompromise.

Case presentation: A 64 year old white man with steroid-induced diabetes mellitus and progressive small-cell bronchial carcinoma despite chemo- and immunotherapy with two checkpoint inhibitors presented with symptoms of lower respiratory tract infection. Community-acquired pneumonia was suspected and empirical broad-spectrum antibacterial treatment was initiated. Chest CT-scan revealed ground-glass opacities and tree-in bud lesions. Cytology of BAL showed extensive cytopathic effects typically caused by infection with herpes virus and PCR confirmation of HSV-1. Acute phase HSV serology was positive for lgG and borderline for lgM. The patient deteriorated clinically due to tumor progress and infection despite high-dose acyclovir therapy and died 2 weeks after admission.

Conclusions: We report an unusual case of fatal HSV-1 pneumonitis due to reactivation in a patient with lung cancer, steroid-induced diabetes and treatment with two checkpoint inhibitors. In immunosuppressed patients with nonimproving pneumonia invasive diagnostic procedures are warranted including cytology and molecular diagnostics.
\end{abstract}

Keywords: Herpes simplex virus, Pneumonitis, Case report, Immune check point inhibitors

\section{Background}

Primary infection with Herpes simplex virus 1 (HSV-1) or 2 (HSV-2) occurs after viral inoculation of mucous membranes or skin. Clinical presentation ranges from asymptomatic courses to symptoms of fever, general malaise and local vesicular rash or potentially fatal organ manifestations [1].

After primary infection the virus remains in a latent stage forming a reservoir in nerve cell bodies. Reactivation can be triggered by physical or emotional stress [2-5],

\footnotetext{
* Correspondence: johannes.sumer@kssg.ch

'Division of Infectious Diseases and Hospital Epidemiology, Cantonal Hospital St. Gallen, Rorschacher Strasse 95, 9007 St. Gallen, Switzerland

Full list of author information is available at the end of the article
}

trauma to the site of primary infection, fever and immunosuppression among other causes. Recurrence usually affects the site of primary infection, but may spread to adjacent areas via peripheral nerves or epithelial cells $[6,7]$.

While rarely seen in immunocompetent adults [8], HSV-1 infection of the lower respiratory tract (LRT) has been described in immunosuppressed and critically-ill patients, where HSV-1 is frequently detected in LRT samples either due to sample contamination from oropharyngeal sites of reactivation or direct extension from the upper airways leading to tracheobronchitis [9].

There is little clinical information whether checkpoint inhibitors have an impact on frequency of HSVinfections, though there is some evidence that these

(C) The Author(s). 2021 Open Access This article is licensed under a Creative Commons Attribution 4.0 International License, which permits use, sharing, adaptation, distribution and reproduction in any medium or format, as long as you give

appropriate credit to the original author(s) and the source, provide a link to the Creative Commons licence, and indicate if changes were made. The images or other third party material in this article are included in the article's Creative Commons licence, unless indicated otherwise in a credit line to the material. If material is not included in the article's Creative Commons licence and your intended use is not permitted by statutory regulation or exceeds the permitted use, you will need to obtain permission directly from the copyright holder. To view a copy of this licence, visit http://creativecommons.org/licenses/by/4.0/. 
immunomodulatory drugs may even be advantageous in clearance of HSV-1 infections (20). Here, we report a case with proven HSV-pneumonitis in a patient with double checkpoint blockage and review the existing literature. To the best of our knowledge this is the first report describing HSV-pneumonitis in a patient receiving corticosteroids and checkpoint inhibitors.

\section{Case presentation}

A 64 year old white male patient was admitted to our tertiary care hospital with dyspnoea, cough and malaise. Past medical history was significant for small-cell bronchial carcinoma (diagnosed 11 months prior) with lymph node, cerebral and adrenal metastases. He was treated with chemotherapy (cisplatin/etoposide) and radiotherapy due to cerebral and mediastinal progress. Second line immunotherapy was established with double checkpoint inhibitor therapy with ipilimumab/nivolumab and additionally dexamethasone $(12 \mathrm{mg} / \mathrm{d}$, started 1 month ago after seizure) because of cerebral edema as well as for immune-related thrombocytopenia under therapy with checkpoint inhibitors. There was a history of steroid-induced diabetes mellitus and subsegmental pulmonary emboli 10 months prior to presentation.

On clinical examination - after two cycles nivolumab/ ipilimumab and still under dexamethasone - the patient was afebrile, hypotensive and normocardic. Pulmonary exam revealed reduced breath sounds bilaterally, poor oxygenation (oxygen saturation 91\% with $2 \mathrm{~L} \mathrm{O} 2$ ) and a respiratory rate of $19 / \mathrm{min}$.

Laboratory examinations on admission revealed a markedly elevated CRP (424 mg/l) and LDH (520 U/l), slightly elevated alanine transaminase $(61 \mathrm{U} / \mathrm{l})$, exacerbated pancytopenia with anaemia (Hb $120 \mathrm{~g} / \mathrm{l}$ ), thrombocytopenia $(82 \mathrm{G} / \mathrm{L})$ and leukocytopenia $(2.1 \mathrm{G} / \mathrm{L})$ with normal granulocytes (absolute 1.3G/l) and lymphopenia $(5 \%$, absolute $0.1 \mathrm{G} / \mathrm{l})$. A chest CT-scan showed signs of pneumonitis with new tree-in bud pattern and peribronchially localized ground glass opacities (Figs. 1 and 2). The bronchial mass was stable compared with a CT performed 3 weeks ago. Legionella antigen in urine was negative.

There was no clinical improvement despite improving signs of inflammation with antibiotic treatment with amoxicillin/clavulanic acid and clarithromycin. Therefore bronchoscopy, which showed macroscopic erythematous lesions in the trachea, and bronchoalveolar lavage (BAL) were performed (Fig. 3). Microscopically a lot of alveolar macrophages and some polymorphonuclear leukocytes (PMN) were visible with normal respiratory flora, so BAL was perfectly consistent with a good sample of the lower airways with an acute inflammation. There was no bacterial or mycobacterial growth on routine culture. A viral respiratory multiplex

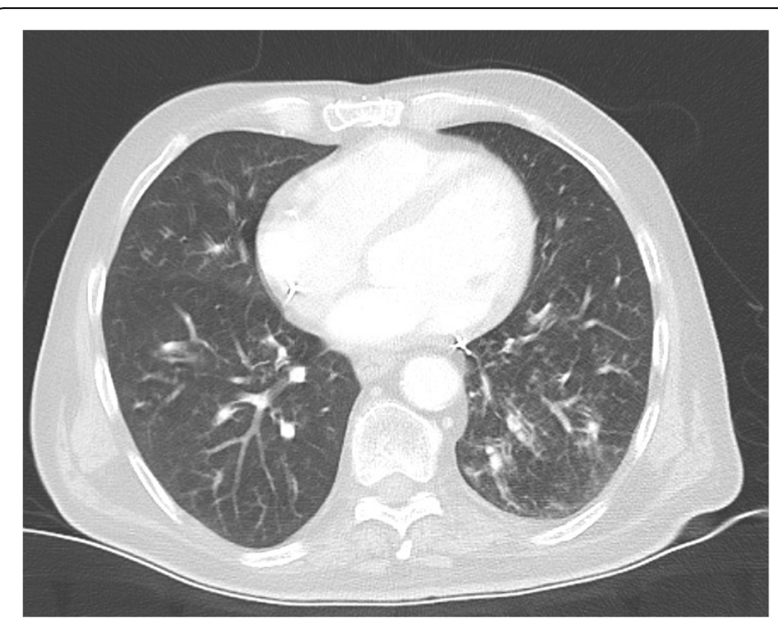

Fig. 1 Axial window CT-scan on day 1 showing pneumonitis with tree-in bud pattern and ground glass opacities

polymerase chain reaction (PCR, AllplexTM Respiratory Panel 1-3 [Seegene)]) and antigen for Pneumocystis jirovecii were negative. Cytology revealed elevated cell count $\left(833 \times 10^{6} / \mathrm{L}\right.$ cells $)$ and neutrophilic granulocytes (68.7\%).

There was an extensive cytopathic effect (Fig. 4) including a positive immunocytochemical stain for HSV$1 / 2$ suggesting HSV-infection in numerous cells (Fig. 5). Fungal or malignant cells were not detected.

Retesting of bronchial secretions with non-quantitative HSV-PCR (Artus ${ }^{\oplus}$ HSV-1/2 QS-RGQ Kit (QIAgen)) detected HSV-1 (Ct value 18.97). Serology (Liaison ${ }^{\circ} \mathrm{HSV}-1 /$ 2 IgG, Liaison ${ }^{\circ} \mathrm{HSV}-1 / 2$ IgM, DiaSorin) showed positive HSV 1/2 IgG (OD-index: 29.0; cut-off: 1.0) and

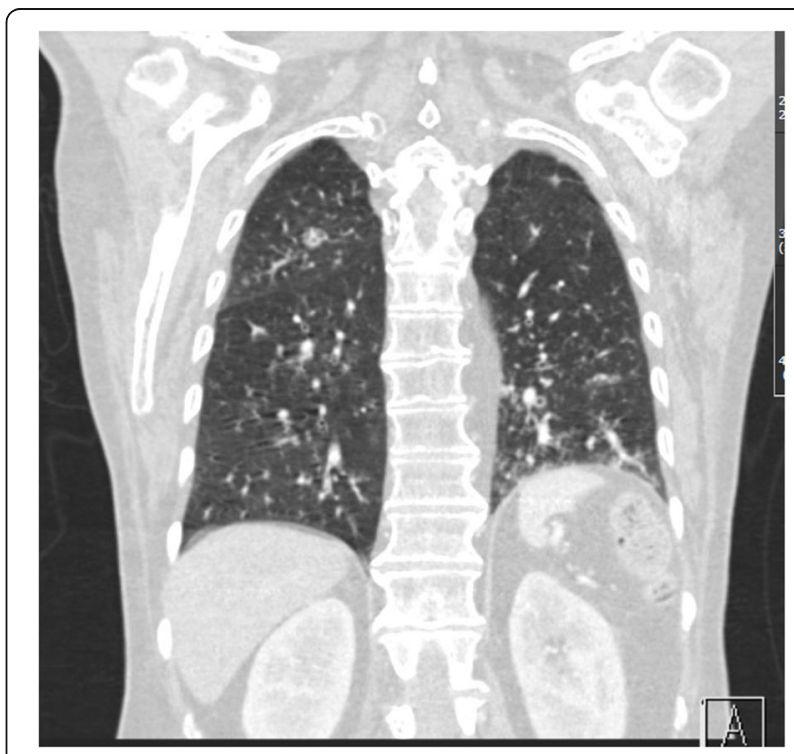

Fig. 2 Coronal window CT-scan on day 1 showing pneumonitis with tree-in bud pattern and ground glass opacities 


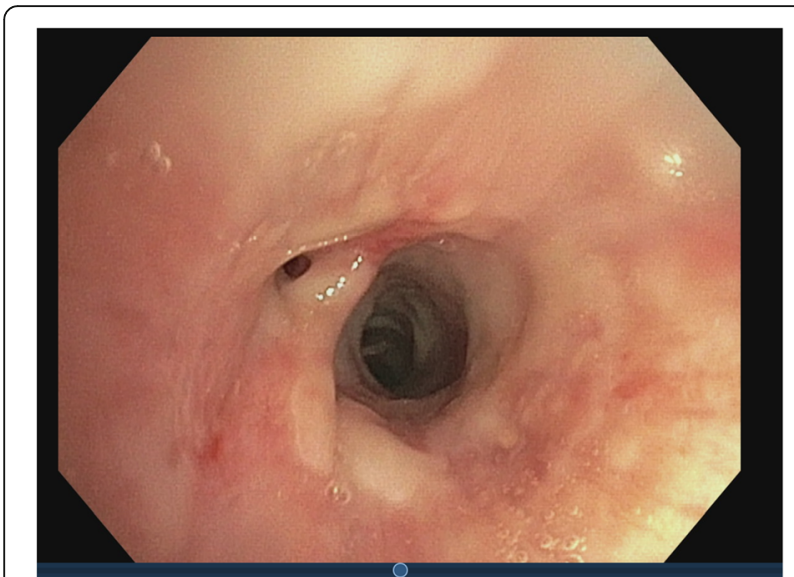

Fig. 3 Bronchoscopy shows reddened mucosa with little white mucus (view in lower lobe left)

borderline positive (OD-index: 0.97; cut-off: 1.1) IgM. Antiviral therapy with acyclovir $10 \mathrm{mg} / \mathrm{kg}$ body weight was started intravenously upon receipt of cytology 3 days after admission. The dose was transiently decreased to 5 $\mathrm{mg} / \mathrm{kg}$ body weight for 1 day, but in light of reduced vigilance suggesting a possible affection of the central nervous system the dose was increased again to $10 \mathrm{mg} /$ $\mathrm{kg}$ body weight on the following day.

Despite improvement of inflammatory parameters the patient continued to deteriorate clinically. With progressive cognitive deterioration cerebral HSV involvement was suspected but was not proven as a diagnostic lumbar puncture could not be performed due to severe and progressive thrombocytopenia (minimum 22G/L) which was attributed to the immunotherapy. A cranial MRI eventually showed progressive cerebral metastases as likely cause of deterioration.

Because of the significantly progressive underlying disease management was altered to palliative care

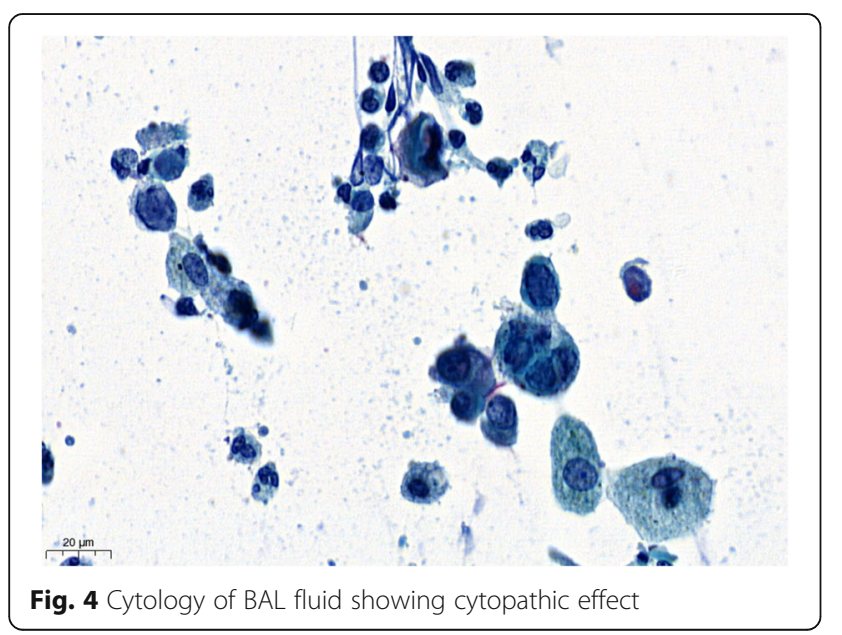

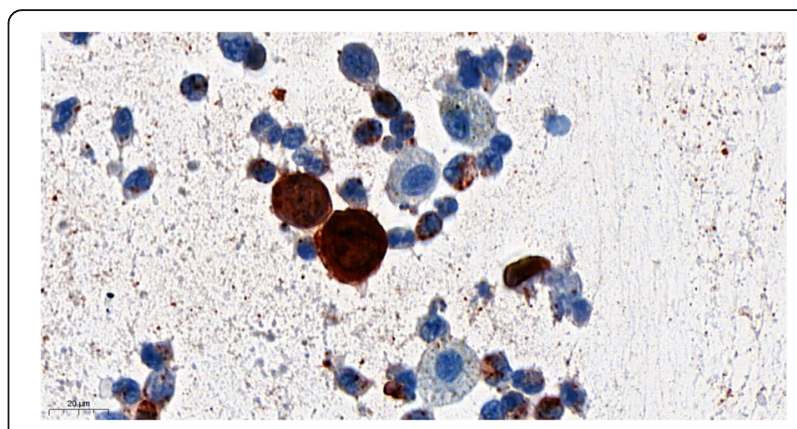

Fig. 5 Immunohistochemistry of BAL, showing immuncytochemic positivity in viral loaded cells. The antibody (Diagnostic Biosystems) reacts with HSV type I and II specific antigens. It reacts with all the major glycoproteins present in the viral envelope as well as with at least one core protein

after 10 days of acyclovir. The patient died 2 weeks after admission. No autopsy was performed.

\section{Discussion}

We report a fatal case of cytologically and PCR proven HSV-1 tracheobronchitis and pneumonitis in a solid organ cancer patient with lymphopenia, steroid-induced diabetes and treatment with dexamethasone and checkpoint inhibitor.

Diagnosis of HSV pneumonia may be challenging due to lack of typical clinical and radiologic features [10]. Given very high seroprevalence worldwide, serology is not useful in most cases except when high IgM titers are present suggesting primary infection, though IgM blips are described during the chronic phase of HSV in apparently health persons [11]. In our case borderline positive IgM and high titers of IgG suggested reactivation and made primary infection unlikely.

Detection of HSV deoxyribonucleic acid by PCR may be only of limited diagnostic utility, since discrimination between relevant infection and simple viral shedding is difficult. However, the low $\mathrm{Ct}$ value in our case reflected a high viral load and confirmed a severe and clinically relevant infection. Our patient had as well tracheobronchitis, evident during bronchoscopy with typical erythematous lesions, as groundglass opacities consistent with HSV pneumonitis.

Proof of HSV infection can be provided by histopathological or cytological examination of infected tissue showing a typical cytopathic effect [12]. As in our case cytological workup showed unequivocal confirmation of HSV-infection and immunocytochemical staining further confirmed diagnosis.

Cytological features suggesting HSV infection in BAL samples have only rarely been described in routinely processed samples [13]. A diagnosis of HSV is suggested based on a number of well described and characteristic cellular changes. Typical signs of infected cells are 
multinucleated, swollen nuclei clustered tightly together leading to a characteristic molding of nuclear contours. The presence of viral inclusions leads to a loss of chromatin pattern and the nuclei are observed to take on an empty homogenized or 'ground glass' appearance with a prominent nuclear membrane, also known as Cowdry type B nuclei $[14,15]$. Strongly eosinophilic inclusions develop in the nucleus known as Cowdry type A inclusions, which are often wedge-shaped or triangular and can appear refractile later during the infective process Cowdry bodies are characteristic but non-specific for HSV [12, 16]. The typical findings in cytology and positive PCR confirmed HSV-1 infection in our patient with the clinical diagnoses of tracheobronchitis and pneumonitis.

Whether HSV was the single causative pathogen leading to the initial respiratory decline or if it occurred as a superinfection of an unidentified bacterial cause is difficult to judge retrospectively since inflammatory parameters decreased during empirical antibiotic therapy in contrast to his clinical condition.

HSV commonly infects patients with impaired cellular immunity, the incidence of pulmonary involvement lies between 36 and 65\% according to Aisenberg et al. [17] and Ramsey et al. [7]. Witt et al. screened a total of 2480 patients with rheumatoid arthritis, vasculitis and SLE retrospectively for pneumonia. Among those there were 63 episodes of hospital admission with respiratory deterioration, that were ultimately diagnosed as pneumonia or pneumonitis. 6 cases $(10 \%$ of admissions for pneumonia) were identified to be associated with HSV-1 in lower respiratory tract, but HSV was suspected to play a causative role only in 2 episodes. Detection of HSV-1 was associated with stronger immunosuppressive regimens and vasculitis [18].

Our patient's risk was likely related to dexamethasone $(12 \mathrm{mg} / \mathrm{d})$, which was started about 1 month before hospitalization and which is known to predispose to infections with Herpesviridae [19]. In addition, lymphopenia is a strong risk fact for infection with herpes viruses. In a cohort study of patients with solid tumors and lower respiratory tract HSV infection Aisenberg et al. described lymphopenia as common and severe lymphopenia was present in nearly half of the entire cohort [17]. Lymphopenic patients are also at risk for Varicella zoster virus, Epstein Barr Virus, Cytomegalovirus and Human Herpes virus 6 infections [20-22]. Our patient had severe lymphopenia which also put him at increased risk for HSV lower respiratory tract infection as shown previously [17].

Bacterial infections like pneumonia, intra-abdominal infections, but also varicella zoster virus infection, pulmonary aspergillosis and pneumocystis pneumonia have been described in cancer patients receiving immune checkpoint inhibitors [23]. There is no intrinsically increased risk of infection - especially VZV or HSVinfections - regarding ipilimumab and nivolumab, but an increased risk seems to be associated with additional immunosuppressive treatments or conditions, particularly corticosteroids [23]. There is even data showing that immune checkpoint inhibitors may reverse the functional exhaustion status of virus-specific $\mathrm{T}$ cells allowing to mount appropriate $\mathrm{T}$ cell responses and virus clearance [24]. In fact, Jeon et al. demonstrated that local PD-L1 blockade in the cornea resulted in enhanced HSV-1 clearance [25]. We did not find reports of severe HSV-infections in patients receiving immune checkpoint inhibitors or evidence for an increased risk. However, Foukas et al. reported a case of severe interstitial pneumonitis with concomitant detection of HHV-6 in a patient under nivolumab [26].

There is equivocal data whether immunosuppression leads to higher mortality in patients with HSV pneumonitis especially those receiving immune checkpoint inhibitors. Interestingly, in an older study of 42 patients with respiratory cultures positive for HSV, immunocompetent patients had a more severe presentation with worse bronchospasm, greater difficulty weaning and worse outcome than immunocompromised patient [27]. Mortality rates of patients with non-solid organ tumors and HSV-isolation from the LRT have been reported as high as $27 \%$ [28]. In a series of 45 patients with proven, probable or possible HSV pneumonia, 38\% suffered from pulmonary malignancy and $22 \%$ died [17].

Since our patient was very acutely ill and immunosuppressed with lymphopenia, steroids and checkpoint inhibitors we treated him with acyclovir, though no guidelines exist regarding treatment indications of HSVpneumonitis. Simoons-smit et al. recommended starting therapy when HSV is isolated from respiratory tract only if it occurs in immunocompromised patients (e.g. patients with malignancies), if there is evidence of pulmonary parenchymal invasion or unexplained clinical deterioration [29]. Our patient fulfilled all three criteria.

Generally there is conflicting data on the benefit from antiviral therapy in HSV pneumonitis [29]. In a small retrospective cohort study by Camps et al. acyclovir treatment showed no effect on overall survival in 28 patients with respiratory specimens positive for HSV [30]. A recent study by Luyt et al. similarly showed no benefit of preemptive use of acyclovir in mechanically ventilated patients with HSV oropharyngeal reactivation in terms of the number of ventilator-free days but improved 60 day survival [31]. In contrast, in a retrospective study acyclovir therapy resulted in lower mortality and all 6 patients with HSV-pneumonitis who received acyclovir survived [17].

In conclusion, we report the first fatal case of HSV-1 pneumonitis in a lymphopenic solid organ cancer patient 
receiving corticosteroids and checkpoint inhibitors. While we do not know what the relative contributions of all these predisposing factors were to the fatal course, it makes this presentation a relevant warning for clinicians taking care of patients with other comorbidities or adjunct immunosuppressive therapies. Despite the notion that checkpoint inhibitors themselves do not increase the risk of HSV-infection, checkpoint inhibitors, particularly combinations as in our case, may often cause immune mediated pneumonitis. Its radiological pattern frequently shows interstitial changes, though there are no pathognomonic findings [24]. In such situations adjunctive treatment with steroids is established, which may be harmful in case of undetected HSV infection. Therefore meticulous diagnostic assessment is warranted, especially in patients with lymphopenia and recent steroid treatment in order to avoid missing alternative diagnoses.

Moreover this case illustrates the importance of obtaining cytological examination in the diagnostic work-up of suspected pulmonary infections, particularly in immunocompromised hosts with refractory pneumonia where it should be combined with broad molecular diagnostics. Further studies are needed to define optimal antiviral treatment and treatment duration as well as to clarify the potential impact of checkpoint inhibitors on risk of herpes and other viral infections.

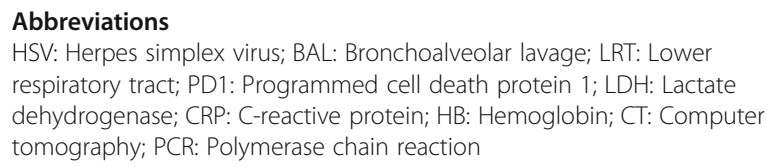

\section{Acknowledgements}

We thank Dr. Christian Gysin (Division of Pneumology, Cantonal Hospital St. Gallen, Switzerland) for providing images of the bronchoscopy.

\section{Authors' contributions}

JS: Involved in patient care, drafted and revised the manuscript. FW: Drafted and revised the manuscript. WA: Involved in patient care, revised the manuscript. NF: Performed cytological assessment and contributed to the pathological section. CA: Involved in patient care, contributed to oncological section. MF: Involved in patient care, contributed to oncological section. MK: Involved in patient care, contributed to the case report. All authors contributed to and approved the final manuscript.

\section{Funding}

No funding was obtained for this article.

\section{Availability of data and materials}

All patient data that support this case report are included in anonymized form in the published article.

\section{Ethics approval and consent to participate}

Not applicable

\section{Consent for publication}

Written informed consent was obtained from the patient for publication of this case report and any accompanying images. A copy of the written consent is available for review by the Editor-in-Chief of this journal.

\section{Competing interests}

The authors declare that they have no competing interests.

\section{Author details}

${ }^{1}$ Division of Infectious Diseases and Hospital Epidemiology, Cantonal Hospital St. Gallen, Rorschacher Strasse 95, 9007 St. Gallen, Switzerland. ${ }^{2}$ Division of Pathology, Cantonal Hospital St. Gallen, Rorschacher Strasse 95, 9007 St. Gallen, Switzerland. ${ }^{3}$ Division of Oncology, Cantonal Hospital St. Gallen, Rorschacher Strasse 95, 9007 St. Gallen, Switzerland. "University of Bern, Bern, Switzerland. ${ }^{5}$ Division of Internal Medicine, Cantonal Hospital St. Gallen, Rorschacher Strasse 95, 9007 St. Gallen, Switzerland.

Received: 15 June 2020 Accepted: 15 December 2020

Published online: 25 January 2021

\section{References}

1. Whitley RJ, Roizman B. Herpes simplex virus infections. Lancet. 2001;357: 1513-8 https://doi.org/10.1016/S0140-6736(00)04638-9.

2. Ives AM, Bertke AS. Stress hormones epinephrine and corticosterone selectively modulate herpes simplex virus 1 (HSV-1) and HSV-2 productive infections in adult sympathetic, but not sensory. Neurons J Virol. 2017;91 https://doi.org/10.1128/JVl.00582-17.

3. Perng G-C, Osorio N, Jiang $X$, et al. Large amounts of reactivated virus in tears precedes recurrent herpes stromal keratitis in stressed rabbits latently infected with herpes simplex virus. Curr Eye Res. 2016;41:284-91 https://doi. org/10.3109/02713683.2015.1020172.

4. Ashcraft KA, Bonneau RH. Psychological stress exacerbates primary vaginal herpes simplex virus type 1 (HSV-1) infection by impairing both innate and adaptive immune responses. Brain Behav Immun. 2008;22:1231-40 https:// doi.org/10.1016/j.bbi.2008.06.008.

5. Ashcraft KA, Hunzeker J, Bonneau RH. Psychological stress impairs the local CD8+ T cell response to mucosal HSV-1 infection and allows for increased pathogenicity via a glucocorticoid receptor-mediated mechanism. Psychoneuroendocrinology. 2008:33:951-63 https://doi.org/10.1016/j. psyneuen.2008.04.010

6. Nicoll MP, Proença JT, Efstathiou S. The molecular basis of herpes simplex virus latency. FEMS Microbiol Rev. 2012;36:684-705 https://doi.org/10.1111/j. 1574-6976.2011.00320.x.

7. Ramsey PG, Fife KH, Hackman RC, et al. Herpes simplex virus pneumonia: clinical, virologic, and pathologic features in 20 patients. Ann Intern Med. 1982:97:813-20 https://doi.org/10.7326/0003-4819-97-6-813.

8. Ishihara T, Yanagi H, Ozawa H, Takagi A. Severe herpes simplex virus pneumonia in an elderly, immunocompetent patient. BMJ Case Rep. 2018; https://doi.org/10.1136/bcr-2017-224022.

9. Luginbuehl M, Imhof A, Klarer A. Herpes simplex type 1 pneumonitis and acute respiratory distress syndrome in a patient with chronic lymphatic leukemia: a case report. J Med Case Rep. 2017;11:329 https://doi.org/10. 1186/s13256-017-1495-9.

10. Chong S, Kim TS, Cho EY. Herpes simplex virus pneumonia: high-resolution CT findings. BJR. 2010;83:585-9 https://doi.org/10.1259/bjr/51409455.

11. Morrow R, Friedrich D. Performance of a novel test for IgM and IgG antibodies in subjects with culture-documented genital herpes simplex virus-1 or -2 infection. Clin Microbiol Infect. 2006;12:463-9 https://doi.org/ 10.1111/j.1469-0691.2006.01370.x.

12. Wilkinson I, Cuschieri $\mathrm{K}$, Monaghan $\mathrm{H}$, et al. Cytological recognition of herpes simplex virus infection in bronchoscopic samples from the respiratory tract. JRCPE. 2011;41:26-8 https://doi.org/10.4997/JRCPE.2011.107.

13. Lapkus O, Elsheikh TM, Ujevich BA, et al. Pitfalls in the diagnosis of herpes simplex infection in respiratory cytology. Acta Cytol. 2006;50:617-20 https:// doi.org/10.1159/000326029.

14. Aslan DL, Pambuccian SE, Prekker FL, et al. Accuracy of herpes simplex virus detection in liquid-based (SurePath) Papanicolaou tests: a comparison with polymerase chain reaction. Diagn Cytopathol. 2008;36:94-103 https://doi. org/10.1002/dc.20732.

15. Gray W, McKee G. Diagnostic cytopathology - Normal respiratory tract and inflammatory conditions. 2nd ed. London; 2003.

16. Wilcox CM, Rodgers W, Lazenby A. Prospective comparison of brush cytology, viral culture, and histology for the diagnosis of ulcerative esophagitis in AIDS. Clin Gastroenterol Hepatol. 2004;2:564-7 https://doi. org/10.1016/s1542-3565(04)00239-3. 
17. Aisenberg $G$, Torres $H$, Tarrand J, et al. Herpes simplex virus lower respiratory tract infection in patients with solid tumors: HSV pneumonia with solid tumors. Cancer. 2009;115:199-206 https://doi.org/10.1002/cncr. 24011.

18. Witt MN, Braun GS, Ihrler S, Schmid H. Occurrence of HSV-1-induced pneumonitis in patients under standard immunosuppressive therapy for rheumatic, vasculitic, and connective tissue disease. BMC Pulm Med. 2009;9: $22 \mathrm{https}: / /$ doi.org/10.1186/1471-2466-9-22.

19. Youssef J, Novosad SA, Winthrop KL. Infection risk and safety of corticosteroid use. Rheum Dis Clin N Am. 2016;42:157-176, ix-x https://doi. org/10.1016/j.rdc.2015.08.004.

20. Giovannoni G. Cladribine to treat relapsing forms of multiple sclerosis. Neurotherapeutics. 2017;14:874-87 https://doi.org/10.1007/s13311-017-05734.

21. Díaz Betancourt ML, Klínger Hernández JC, Niño Castaño VE. Profound CD4+ T lymphocytopenia in human immunodeficiency virus negative individuals, improved with anti-human herpes virus treatment. Colomb Med (Cali). 2012;43:305-11.

22. Handous I, Achour B, Marzouk M, et al. Co-infections of human herpesviruses (CMV, HHV-6, HHV-7 and EBV) in non-transplant acute leukemia patients undergoing chemotherapy. Virol J. 2020;17:37 https://doi. org/10.1186/s12985-020-01302-4.

23. Del Castillo M, Romero FA, Argüello E, et al. The spectrum of serious infections among patients receiving immune checkpoint blockade for the treatment of melanoma. Clin Infect Dis. 2016;63:1490-3 https://doi.org/10. 1093/cid/ciw539.

24. Rutigliano JA, Sharma S, Morris MY, et al. Highly pathological influenza a virus infection is associated with augmented expression of PD-1 by functionally compromised virus-specific CD8+ T cells. J Virol. 2014;88:163651 https://doi.org/10.1128/JVI.02851-13.

25. Jeon S, Rowe AM, Carroll KL, et al. PD-L1/B7-H1 inhibits viral clearance by macrophages in HSV-1-infected corneas. J Immunol. 2018;200:3711-9 https://doi.org/10.4049/jimmunol.1700417.

26. Foukas PG, Tsiodras S, Economopoulou P, et al. Concomitant human herpes virus 6 and nivolumab-related pneumonitis: potential pathogenetic insights. IDCases. 2018;11:101-3 https://doi.org/10.1016/j.idcr.2018.01.013.

27. Schuller D, Spessert C, Fraser VJ, Goodenberger DM. Herpes simplex virus from respiratory tract secretions: epidemiology, clinical characteristics, and outcome in immunocompromised and nonimmunocompromised hosts. Am J Med. 1993;94:29-33 https://doi.org/10.1016/0002-9343(93)90116-7.

28. Prellner T, Flamholc $L$, Haidl $S$, et al. Herpes simplex virus--the most frequently isolated pathogen in the lungs of patients with severe respiratory distress. Scand J Infect Dis. 1992;24:283-92 https://doi.org/10.3109/ 00365549209061333.

29. Simoons-Smit AM, Kraan EM, Beishuizen A, et al. Herpes simplex virus type 1 and respiratory disease in critically-ill patients: real pathogen or innocent bystander? Clin Microbiol Infect. 2006;12:1050-9 https://doi.org/10.1111/j. 1469-0691.2006.01475.x.

30. Camps K, Jorens PG, Demey HE, et al. Clinical significance of herpes simplex virus in the lower respiratory tract of critically ill patients. Eur J Clin Microbiol Infect Dis. 2002;21:758-9 https://doi.org/10.1007/s10096-002-0809y.

31. Luyt C-E, Forel J-M, Hajage D, et al. Acyclovir for mechanically ventilated patients with herpes simplex virus oropharyngeal reactivation: a randomized clinical trial. JAMA Intern Med. 2019; https://doi.org/10.1001/ jamainternmed.2019.5713.

\section{Publisher's Note}

Springer Nature remains neutral with regard to jurisdictional claims in published maps and institutional affiliations.

Ready to submit your research? Choose BMC and benefit from:

- fast, convenient online submission

- thorough peer review by experienced researchers in your field

- rapid publication on acceptance

- support for research data, including large and complex data types

- gold Open Access which fosters wider collaboration and increased citations

- maximum visibility for your research: over $100 \mathrm{M}$ website views per year

At BMC, research is always in progress.

Learn more biomedcentral.com/submissions 